\title{
Evaluation of Social and Psychological Factors Affecting the Feeling of Security of Women in Iran
}

\author{
Mohadeseh Amin \\ Department of sociology, Islamic Azad University, Kerman Branch, Kerman, Iran \\ Dr. Alireza Sanat Khah \\ Assistance professor, Department of sociology, Islamic Azad University \\ Kerman Branch, Kerman, Iran Corresponding authors
}

Doi:10.5901/mjss.2016.v7n3s2p123

\begin{abstract}
This article is trying to examine social and psychological factors affecting social security for women over 18 years in Kerman. The population is consisted of female employees over 18 years (equivalent to 357,963 persons) in Kerman and the research sample is 400 employees and cluster and simple random methods are used for sampling. Regarding the theoretical framework, the integration of theories of Durkheim, Buzan, Jenkins and Walter Rekles and colleagues were used to explain the social factors and theories of Sigmund Freud and David Riesman have been used to account for psychological factors affecting women's sense of social security. The results suggest that the variables that have a direct and positive impact on the sense of security in the highest to lowest impact are respectively as: perception of social control (0.339) and female identity (0.283) and social capital (0.172) perception of social order (0.131) and the perception of appropriate clothing (0.108) and variables that have less an negative impact are nearness to the areas of high crime (0.113-) and religious adherence (0.73-). The results also suggest that social control of women, female identity, social capital, social order and proper coverage and religious commitment are effective in a sense of security in women and can give women a sense of security.
\end{abstract}

Keywords: sense of security, social order, social control, religiosity, social capital.

\section{Introduction and Problem Statement}

Security is considered of basic human needs and motivations, so that with its deterioration, the peace of mind of man is lost and anxiety and unrest take its place (Kahe, 133: 2005). Social security is related to the domains of privacy in connection with other individuals, organizations and governments that are continually face this realm during their life (Mueller 8, 2000). Social Security has both objective and subjective aspects and its subjective dimension is to say sense of security.

This feeling results from direct and indirect experience of the conditions and environment and different people experience it in different forms. Feeling of insecurity increased cost of social interaction (Hasanvand and Hasanvand, 60: 2011) and on the other hand impairs the social trust and causes the development of personal and social apathy, and threatens unity and social cohesion (Hasanvand and Hasanvand, 60: 2011). Among other things, the gender factor has a significant role in the adoption of this vulnerability. (Hossein Zadeh and Sade Miri , 48: 2011). Women make up half of society and in recent years, especially in large cities, their social presence, to pursue higher education, employment, political participation, and ... has risen. Today, the high percentage of women jobseekers, after recruitment, faced with the lack of security and dignity at their workplace. Due to the strategic location of Kerman and its nearness to the transit route for drugs, in this study, we tried to examine social security for women in Kerman and examine social and psychological factors affecting it.

\section{Research Literature}

Many of the researchers studied the effect of socio-cultural and economic and psychological factors on the sense of security of women. Norozie and Folady (2008) in their study have proved that sense of security in the location, economic and social status and sense of social order variables have effective and positive effect and religious commitment variable has negative and inverse effect on social security of women. The results of these studies are 
consistent with Kamran and Ebadie (2000) and Hasanvand (2011) - Nyazy and et al (2011).

Taheri and colleagues (31: 2012) in their study of the relationship between the the role of police and feeling of safety in the city, examined security in four dimensions: financial, physical, social, and intellectual, and the role of police in the three dimensions of performance, enthusiasm, and ability.

Their results showed that the mean score of respondents according to four dimensions of security, most related to intellectual security (3/35), and then the collective security (3/29), followed by financial security (2/69) and the safety was the final ranking (2/42). Shahdad Khage Askari and Zangani Zadeh Zanjan (142: 2008) in their investigation on the causes and consequences of the fear of crime among women observed a relationship between media consumption and social security such that the more the use of the media is concerned to see news and events; the lower is sense of security."

Afshar, Zeinol Abedin (2006) in their study concluded that social security is lower than the average of women in Tehran and factors such as the practice of law, social tolerance and social norms affect them. The findings of Bayat, Bahram (2009) showed that the sense of insecurity in terms of gender, region of residence, marital status and age of the respondents is different and Nagibie (2008; quoted from Arizie, 1391) in identifying women's problems in social security municipal affairs concluded that about $74 \%$ of women believe that crime rates in the community are significant. About $66 \%$ of women take caution when they hear crimes, or read it in their social relationships. About $65 \%$ of female drivers have experienced with a lot of harassment. About $74 \%$ of women feel jittery in dark passages. About $63 \%$ said that the society is not safe for women at all (Nagibie, 2011). Bounty and Pascal (2007) showed that women and girls avoid living in the dangerous and insecure neighborhoods according to official statistics of crime and are well-known as the troubled neighborhoods. Weaver (2010) in his study about the effect of social support relationship of relatives in the United States subject to the social security did show that social support and feelings of women in a relationship indicated that there is a relationship between social support and security of women.

\section{Theoretical Framework}

In order to scientifically explain the sense of security of women in Kerman, we require integration of ideas in the fields of sociology and psychology. One of the sociological issues that can have a close relationship with the women's sense of security is their perception of the social order. Women interpretation of issues and problems in society (security issues) and mining cause of these problems can offer a firm explanation of the feeling of security. On the other hand, Durkheim treats social cohesion as the survival of society (and Norozie and Foladie, 133: 2009) which ensures the social order and its associated disabilities share a common morality and ethics. Moral and ethical values that govern women's ordination in this area can be important.

Walter Rekls and et al. (1996 quoted from Ahmadie and Chaldean, 6: 2011) focused on residence security. They also believe that many people are deviant in some sectors of society, which means that foreign control was not strong enough to deal with the motivation of deviant behavior and believe that safety behaviors concerning to the security feeling come from security in more living environment and regarding to the high-risk areas, differentiated economic zones (north or south of the city) is also essential.

Other topics that highlight the field topic are gender identity of female. Jenkins believes that identity is a process and continuous process that is produced and reproduced over time. (Gol Mohammadi, 2002: 324; quoted in the Norouzi, 2009) and help women in the various areas of work and their education in redefining their female identity.

Social security can change in communication with social networks and also his confidence in others and participation in social structures. From the viewpoint of Putnam, social capital refers to the ability of the community to create a variety of voluntary associations of people to work with one another and thus maintain democratic pluralism. Putnam (2000), knows social capital as a set of trust, norms and networks concepts that create communication and optimal participation of members of the community and eventually will provide their mutual benefits. Based on the theoretical framework, the following hypothesis can be stated as:

It seems that there is a relationship between the perception of women in the social order and their feeling of social security in Kerman.

Based on the theoretical framework hypothesis can be stated thus:

It seems that there is a relationship between the perception of women's social order and their social security Kerman. (Pearson Correlation 435, Sig=0.000)

It seems that there is a relationship between the perception of social control of women and their feeling of social security in Kerman. (Pearson Correlation. .637 Sig=0.000

It seems there is a relationship between the perception of women from suitable suit and their feeling of social 
security in Kerman.

(Pearson Correlation. sig $=0.000) .422$

It seems there is a relationship between the evaluation of women in the safety of region of residence and a sense of security in Kerman.

(Pearson Correlation Sig=0.164).

It seems that there is a relationship between the location close to high crimes and social security of women in Kerman. (Pearson Correlation - 160. Sig=0.001).

It seems that there is a relationship between religious commitment and sense of social security for women in Kerman.( Pearson Correlation .300 .sig=0.000).

It seems there is a relationship between the female social identity and social security of women in Kerman. (Pearson Correlation618. Sig=0.000).

It seems that there is a relationship between social capital and social security of women in Kerman (Pearson Correlation. 518. Sig $=0.000$ ).

It seems that there is a significant relationship between the residential neighborhoods based on the economic situation with a sense of security. (Pearson Chi-Square. 164. Sig=0.002)

\section{Methodology}

The method used in this study is a combination of methods (quantitative-qualitative). The reason for choosing this method refers to the nature of subject, as the sense of security is a subjective method that cannot be completed without considering the women's interpretations. On the other hand, there are some social, political, and cultural limitations in Iran that it is necessary to use this method; this necessity can be felt more about the subjects that related to police.

The statistical population is consisted of all women over 18 years of in Kerman and according to the census of 1393, 357963 women living in Kerman and based on Kokaran formula, the sample size is 384 women. Cluster sampling method was used in 5 areas in Kerman.

To test the validity, construct validity was used. Reliability was computed using Cronbach's alpha coefficient for these variables: social security with 12 items (671.) and the social order with 7 items (799) and a sense of social control with 7 items (909) and adequate coverage of women with 6 items (700) and secure location with the 6 items (837.) and proximity to areas of high crime with 6 items equal to (853.) and religious commitment with 10 items equal to (905) and social identity with 8 items (753) and social capital of with items (875.) and social class with (756.)

\section{Research Findings}

In this study, 400 women over 18 years of Kerman were studied. The average age of the respondents is 31 years in about $47 \%$ of the respondents were married and $43 \%$ were single and 9 percent are divorced and educational status of respondents is in a way which approximately $43 \%$ and $25 \%$ are of bachelor degree and $32 \%$ of are below their associate degree. Regarding to the sense of security, it should be noted that unfortunately the sense of security among women in Kerman is lower than 2.5 (out of 5 ).

In respect to the social control, the scores of all items 2.5 to 3 (out of 5 ) and the lowest score is obtained on police efforts to collect mob (2.98 of 5). About the perception of women from covering, the scores of all items between are 2.5 to 3.5 (out of 5) that more women in Kerman believe that the veil for women can bring security (3.49 of 5). These results show that most of people know the real value of woman fairly in veil.

In the case of female identity, the scores of all items are above 2.5 (out of 5), and the highest score is related to the proudness woman (3.89 of 5) and the lowest is related to social activities such as women's participation in the campaign (2.14 out of 5), the results show that women are relatively happy with their female identity.

\section{Regression Model Test of the Research}

In order to better understand the psychological and social factors affecting women's security, various variables are entered into the regression equation. At first, the correlation of variables was studied and the variables that significantly correlated with the dependent variable in space have been entered.

Variables of perception of order, perception of social control, the perception of women from covering, proximity to areas of high crime, residential neighborhood on the basis of economic status, religious commitment, female identity, social capital has been entered as independent variables and their relationship with a sense of security is discussed. 
The above regression equation is done Enter manner. $\mathrm{R}$ Square has been obtained for the regression model equal to 569. This means that $9 / 56$ of the dependent variable is affected by the independent variables were entered into the model. $F$ test showed that the variables obtained the necessary utility had to enter the regression model $(F=64.465$, sig $=0.000$ ). Beta coefficients and non-standard variables specified in the table below.

As specified in the table, the perception of social control variable is the most influenced in feeling safe. On the other hand, proximity to areas of high crime and a sense of security has reverse relationship; it means that more proximity of person to high-risk and disreputable areas, the sense of security is less. The results in the above table are clearly visible.

Table 1: Standard and non-standard coefficients of the variables

\begin{tabular}{|c|c|c|c|c|c|}
\hline \multirow[b]{2}{*}{ Model } & \multicolumn{2}{|c|}{ Unstandardized Coefficients } & \multirow{2}{*}{$\begin{array}{c}\text { Standardized Coefficients } \\
\text { Beta }\end{array}$} & \multirow{2}{*}{$\mathrm{t}$} & \multirow{2}{*}{ Sig. } \\
\hline & B & انحر اف استاندارد & & & \\
\hline (Constant) & -1.152 & 2.000 & & -.576 & .565 \\
\hline Perception of social order & .203 & .059 & .131 & 3.435 & .001 \\
\hline Perception of social control & .426 & .056 & .339 & 7.613 & .000 \\
\hline Perception of suitable cover & .166 & .061 & .108 & 2718 & .007 \\
\hline Proximity to centers of crime & -.136 & .053 & -.113 & -2.557 & .011 \\
\hline $\begin{array}{l}\text { Religious commitment } \\
\text { Women's identity } \\
\text { social capital }\end{array}$ & -.071 & .040 & -.073 & -1.775 & .077 \\
\hline $\begin{array}{l}\text { Religious commitment } \\
\text { Women's identity } \\
\text { social capital }\end{array}$ & .381 & .061 & .283 & 6.190 & .000 \\
\hline $\begin{array}{l}\text { Religious commitment } \\
\text { Women's identity } \\
\text { social capital }\end{array}$ & .099 & .026 & .172 & 3.757 & .000 \\
\hline
\end{tabular}

\section{Conclusions}

This study examines the social and psychological factors affecting social security for women over 18 years in the city of Kerman. Over all, the results of research and statistical activities affirmed the significant and positive relationship between research and social security among women in the studied population. In this study, women's perception of social control system has a significant relationship with a sense of social security. The results of research are consistent with

Norozie and Fouladie results.

Female identity variable is one of the main variables affecting the sense of identity and social security. Jenkins believes that identity is a process and continuous process that is produced and reproduced over time (Gol Mohammadi, 2002: 324) and the entrance of women in the various areas of work and the school will help them to redefine their feminine identity. The results showed that the more value and importance of women in society and the academic and professional fields increase the feeling of security in women. Another variable that affects the sense of security is a component of social capital, social capital, trust and partnership.

The results showed that the more women trust to people the same degree, they feel stronger security and social participation of women in the various fields of social, political, cultural, have wider feeling of security.

Another variable that can affect the security is the kind of cover (hijab), which the effect of this type of cover is less than other variables. The proximity to the areas of high crime variable residence based on the economic situation affects the sense of security. These results are the same with results of Rekls and Walter et al (1996).

\section{References}

Afshar, g., 2006, Social Security of Women in Tehran, Master's Thesis, Faculty of Social Sciences, Tehran University.

Bayat b., 2009, Study of Factors Affecting the Security of Citizens in Tehran (with an emphasis on mass media, police and crime), Journal of Social Discipline, First Year, Issue 1, pages 55-31.

Hasanvand, or. And Hasanvand, a., 2011, The Study of Factors Affecting Social Security in Youth (case study in Selseleh city ), 
Journal of Order and Security Police, Issue 4, Pages 80-57.

Hossein Zadeh, Ali. H. And Sade Miri , g., 2011, The Study of Impact of Social - Political Factors on the Sense of Security (A Case Study: The citizens of the city of llam), a specialized journal of Social Science in Islamic Azad University, Shosh Tar Branch, 15 Year, Issue 15, pages 54-27.

Zanjan Zadeh Azazie , H. (2008) Causes and Consequences of the Fear of Crime among Women: A case study in Hormozgan, Bandar Abbas, Islamic Republic of Iran, social studies, Issue 1 , fall.

Taheri, Z; Rabbani, Rasol , Adibie Sadeh, M., (2009) , The relationship between the Police and Feel Safe in the city, Security Strategic Studies and Social Order, No. 1, Spring, S21-38

Arizie, F. and Muhammadie, or. and S, G., 2012 , the Relationship between Socio-Demographic Characteristics of Women Who Feel Safe in Public Places in Bandar Abbas, Journal of Urban Studies, Issue 4, pages 110-91.

Kamran, F. And Ebadati Nazarloo, S., 2010, To Evaluate the Socio-Economic Factors Affecting on Women Feeling Relaxed and Social Security in Sociology Graduate Student of Tehran University, Social Research Quarterly, Issue 6, Pages 56-43

Kahh, I 2005, Proceedings of the International Conference of Social Security, Volume, Golponeh Publications, Tehran.

Norozie, F and Fooladi Sepehr, 2009, The investigation of the social security in 29-15 year old women and Social Factors Affecting it, the Strategy Quarterly, eighteenth year, No. 53, pages 159-129.

Niazi and Shafahi Moghaddam, A and Shad Far, A, 2012, The Examination of the Relationship between Social Capital and Social Security of Women in the Northern Regions $(1,2)$ and Downtown $(20$ and 19) Tehran, Journal of Youth Studies Sociology, Issue 3 , pages $160-131$. 